\title{
PENGARUH KELAS UMUR TERHADAP PRODUKTIVITAS GETAH POHON PINUS MERKUSII DI KPH BANDUNG UTARA
}

\section{Effect of Age Class on Productivity of Gum Merkusii Pine in KPH Bandung Utara}

\author{
Nirma Audina ${ }^{1)}$, Raizal F. Solihat ${ }^{2)}$, Asep Purwanto ${ }^{3)}$ \\ ${ }^{1)}$ Perum Perhutani Divisi Regional Jawa Barat dan Banten \\ ${ }^{2,3)}$ Fakultas Kehutanan Universitas Winaya Mukti
}

\section{Diterima 10 April 2020/Disetujui 13 April 2020}

\begin{abstract}
The object of research is to determine the effect of age classes on the productivity of pine resin (Pinus Merkusii). In addition to this, this research also aims to explore the possibility of the effect of diameter on productivity. This research was carried out in RPH Ujung Berung, BKPH Manglayang Barat KPH Bandung Utara, and Divisi Regional Jawa Barat \& Banten. The time of the research was conducted from September to November 2018. The purpose of this study was to determine the effect the effect of age classes, diameter difference and interaction between age and diameter. Based on the results of the research it can be concluded that the productivity of pine resin is affected by the age class. It showed by data increased in age class followed by increased productivity of resin. Age Class IV is 13.26 grams, Age Class V is 30.74 grams and Age Class VI is 61.17 grams. There is a tendency for latex production to increase by the time the tree grow older to a certain age. Diameter affect the productivity of resin, the greater the growth of tree diameter, the more abundant the resin can be and the production of pine resin will increase. This is shown by data increased in diameter followed by increasing resin productivity, in diameters of 20-23 productivity of resin is 29.7 grams, diameter 24-27 productivity of resin is 36.44 grams and diameter 28-31 productivity of resin is 38.95 grams. Age classes difference affect the amount of resin production, the older the tree ages, the larger diameter will be, and finally affect to resin productivity, up to a certain age limit.
\end{abstract}

Keywords: age class differences, diameter differences 


\section{PENDAHULUAN}

Potensi hutan tropis Indonesia juga memegang peranan penting dalam menunjang kebutuhan bahan baku berbagai industri, misalnya industri kayu, plywood, pulp dan kertas. Salah satu jenis pohon hutan yang mempunyai peranan penting dalam bidang industri adalah pohon tusam (Pinus merkusii). Pinus merupakan pohon penghasil kayu bernilai ekonomis tinggi dan juga penghasil getah atau disebut pohon berfungsi ganda. Salah satu hasil hutan non kayu yang penting dalam meningkatkan nilai ekonomi dan kesejahteraan masyarakat adalah getah pinus yang kemudian dapat diolah menjadi gondorukem.

Produk turunan dari getah pinus sebagai salah satu jenis hasil hutan bukan kayu (HHBK) sudah masuk dalam sistem perdagangan internasional. Perdagangan getah pinus (gondorukem dan terpentin) Indonesia di pasar internasional menempati urutan ketiga setelah China dan Brasil. Sebagai produsen derivat gondorukem dan terpentin urutan ketiga, Indonesia melalui Perum Perhutani mampu menembus $10 \%$ total produksi dunia setelah China (70\%) dan Brasil (11\%). Produksi getah pinus Indonesia berkisar 900.000 ton/tahun dan yang diperdagangkan di pasar getah internasional mencapai $50.000-60.000$ ton/tahun. (Lempang, 2017).

Salah satu kegiatan yang dilaksanakan oleh Perum Perhutani yaitu pengusahaan getah pinus. Pinus merupakan kelas perusahaan yang mendapat perhatian khusus selain kelas perusahaan jati. Kelas Perusahaan pinus lebih ditekankan untuk menghasilkan getah yang kemudian digunakan untuk memproduksi gondorukem dan terpentin.

Pengusahaan getah pinus semakin berkembang karena permintaan getah pinus di Indonesia maupun di dunia semakin meningkat. Oleh karena itu, perlu dilakukan upaya untuk meningkatkan produktivitas getah pinus di Indonesia. Salah satu cara untuk meningkatkan produktivitas getah pinus dapat dilakukan dengan cara melakukan penyadapan pada tanaman yang mempunyai diameter yang besar.

Produktivitas getah pinus dipengaruhi oleh beberapa faktor antara lain faktor dari dalam pohon itu sendiri seperti jenis, diameter dan umur tegakan. Produksi getah perlu diketahui untuk memperoleh informasi mengenai kelas umur dan individu pohon yang bergetah banyak. Informasi ini sangat penting untuk keperluan pengelolaan produksi getah pinus di masa yang akan datang. Dengan demikian, diperlukan penelitian mengenai pengaruh kelas umur terhadap produktivitas getah pohon Pinus merkusii dengan Studi Kasus di RPH Ujungberung BKPH Manglayang Barat KPH Bandung Utara Perum Perhutani Divisi Regional Jawa Barat dan Banten. Penelitian ini dilakukan untuk 
mengetahui informasi mengenai perbedaan pengaruh kelas umur pohon Pinus merkusii terhadap produktivitas getah yang berbeda sehingga dapat diketahui.

\section{METODE PENELITIAN}

Penelitian dilakukan 3 (tiga) kali ulangan pada setiap Kelas Umur (KU) per 12 hari sekali di hutan lindung Wilayah Perum Perhutani BKPH Manglayang Barat, KPH Bandung Utara. Alat yang digunakan untuk kegiatan penelitian ini adalah sebagai berikut : Label Pohon (fiber), Benang Woll, Timbangan, Plastik, Gunting, Tallysheet, Alat Pengeruk (sendok), camera. Bahan yang digunakan dalam penelitian ini adalah tegakan pohon Pinus merkusii sudah siap sadap yang berada pada Kelas Umur IV, Kelas Umur V dan Kelas Umur VI.

Jenis data yang dikumpulkan terdiri atas data primer dan data sekunder. Data primer meliputi data hasil penyadapan getah pinus melalui pengambilan getah dengan melakukan kegiatan penimbangan getah pinus pada pohon sampel di tingkat umur yang berbeda. Penyadapan getah dengan menggunakan metode koakan hasilnya yaitu berupa data hasil penyadapan getah pinus. Data sekunder meliputi data mengenai letak dan luas areal, topografi, tanah, keadaan vegetasi, iklim dan peta lokasi penyadapan. Selain itu data sekunder diperolah dengan melihat data yang tersedia dilokasi penelitian.

Pohon yang digunakan dalam penelitian adalah pohon yang mempunyai kriteria sebagai berikut :

1. Pohon sudah siap sadap yang berada di KU IV, KU V dan KU VI

2. Perlakuan semua pohon yang akan diuji menggunakan zat stimulant Socepas dengan dosis $2 \mathrm{CC}$ per quare atau koakan perpohon dengan jarak penyemprotan $20 \mathrm{~cm}$.

3. Mempunyai bonita yang sama disetiap petaknya.

4. Kondisi koakan dan jumlah koakan pada pohon sama

5. Mempunyai diameter batangnya lurus dengan kisaran besaran : $\varnothing 20-23 \mathrm{~cm}$, $\emptyset 24-27 \mathrm{~cm}$ dan $\emptyset 28-31 \mathrm{~cm}$. Besaran standar yang digunakan mengacu pada kondisi fisik dilapangan.

6. Tidak cacat, betajuk lebat dan tidak terserang hama penyakit.

Penentuan sampel pohon dilakukan dengan mengambil sampel pohon sebanyak $1 \%$ dari banyaknya pohon dalam suatu petak yang sudah memenuhi kriteria pohon uji. Kriteria pohon uji yang dimaksud yaitu pohon yang berada di KU IV, KU V, KU VI, pohon yang mendapat perlakuan sama, pohon yang 
diameter batangnya lurus serta dengan kisaran besar yang sudah ditentukan, dan terakhir kriteria pohon uji yaitu tidak cacat, bertajuk lebat dan tidak terserang hama penyakit. Pengambilan sample pohon menggunakan proposive sampling agar pengambilan sampel pohon lebih representatif. Untuk menghitung jumlah pohon sempel dihitung dengan menggunaakan rumus :

$\mathrm{n}=1 \% \mathrm{x}$ jumlah pohon yang mem enuhi kriteria

Keterangan :

n : Jumlah pohon sampel dalam setiap Kelas Umur

Sistem penyadapan getah yang akan digunakan dalam penelitian ini adalah menggunakan sistem quare dengan Intensitas Sampling (IS) 1\% dari jumlah pohon yang sudah ditentukan (risalah pohon). Langkah pertama adalah dengan memilih pohon sesuai dengan kriteria yang sudah ditentukan dengan jumlah pohon disesuaikan dengan perhitungan Intensitas Sampling (IS). Selanjutnya memberi nomor pohon yang sudah dipilih serta mengukur diameter setiap pohon dan menuliskan hasilnya ke dalam tally sheet. Langkah kedua adalah pemungutan getah pada pohon sampel dilakukan 12 (dua belas) hari dengan tiga kali pembaharuan quare sepanjang $5 \mathrm{~mm}$, kemudian getah yang keluar diambil dari batok dan dimasukan kedalam kantong plastik bening. Setiap plastik diberi nomor sesuai nomor pohon yang dipungut. Langkah ketiga adalah menimbang getah tersebut dan menuliskan hasil timbangan ke dalam tally sheet yang sudah disediakan. Kegiatan ini dilakukan pada semua pohon sampel yang telah diberi nomor. Penelitian ini dilakukan selama 1 (satu) kali dalam satu periode selama 12 (dua belas) hari.

Data hasil pengamatan dilapangan kemudian diolah menggunakan analisis Rancangan Acak Lengkap (RAL) faktorial dengan dua faktor. Faktor pertama adalah kelas umur berbeda yang terdiri dari 3 tingkatan kelas umur yaitu Kelas Umur (KU) IV, Kelas Umur (KU) V dan Kelas Umur (KU) VI. Faktor kedua adalah diameter pohon pinus yang dibagi menjadi 3 kategori diameter pohon diantaranya $\varnothing$ 20-23, Ø 24-27 dan $\varnothing ~ 28-31$. Perlakuan dalam penelitian ini adalah hasil kombinasi antar faktor kelas umur dengan diameter. Dengan demikian, dalam penelitian ini terdapat 3 × 3 × 3 kombinasi atau 27 kombinasi. 


\section{HASIL DAN PEMBAHASAN}

\section{Keadaan Lokasi Penelitian}

Konfigurasi lapangan dan kawasan hutan BKPH Manglayang Barat pada umumnya berbukit. Pada petak 41a1 dengan tahun tanam 2000 (18 th), ketinggian 1.246 mdpl, jenis tanah Latosol, tekstur lempung, struktur tanah agak liat, solum sedang, kesuburan sedang, komoditas penggarap kopi termasuk dalam Bonita III. Petak 42c denga tahun tanam 1995 (23 th), ketinggian 1.420 mdpl, jenis tanah Latosol, tekstur lempung, struktur tanah agak liat, solum dalam, kesuburan subur, komoditas penggarap kopi termasuk dalam Bonita III. Sedangankan pada petak 49 b dengan tahun tanam 1991 (27 th), ketinggian 1.423 mdpl, jenis tanah Latosol, tekstur lempung, struktur tanah agak liat, solum sedang, kesuburan sedang, komoditas penggarap kopi termasuk dalam Bonita III.

\section{Sampel Penelitian}

Petak yang dijadikan sebagai lokasi penelitian pada KU (Kelas Umur) IV yaitu petak 41a1 seluas 8,40 Ha dengan jumlah pohon 1.745, KU (Kelas Umur) V yaitu petak 49 b seluas 4,80 Ha dengan jumlah pohon 1.737 dan KU (Kelas Umur) VI yaitu petak $42 \mathrm{c}$ seluas 17,00 Ha dengan jumlah pohon 2.351. Masingmasing petak diambil sampel sebanyak 18 pohon yang diambil dari $1 \%$ dari jumlah pohon yang sudah ditentukan. Jumlah pohon ditentukan pada saat kegiatan risalah pohon.

Pengamatan yang dilaksanakan di lapangan sebanyak 3 (tiga) kali pemungutan getah pada KU (Kelas Umur) IV, KU (Kelas Umur) V, dan KU (Kelas Umur) VI, dengan interval waktu pengambilan setiap 12 (dua belas) hari sekali. Pada KU (Kelas Umur) IV, KU (Kelas Umur) V, dan KU (Kelas Umur) VI masing-masing dikelompokkan menjadi 3 kelas diameter yaitu diameter 20-23 cm, diameter 24-27 dan $28-31 \mathrm{~cm}$.

\section{Pengaruh Kelas Umur}

Pohon yang dijadikan sampel sebanyak 18 pohon pada masing-masing kelas umur, dan didapatkan data hasil produktivitas getah pinus (Tabel 1). Berdasarkan Tabel 1 didapat hasil produktivitas getah pinus merkusii pada KU (Kelas Umur) IV pada ulangan 1 adalah 46,75 gram, ulangan 2 adalah 12,33 gram dan ulangan 3 adalah 24,55 gram. Pada KU (Kelas Umur) V pada ulangan 1 adalah 56,00 gram, ulangan 2 adalah 59,92 gram dan ulangan 3 adalah 74,08 gram. Sedangkan pada 
KU (Kelas Umur) VI pada ulangan 1 adalah 143,52 gram, ulangan 2 adalah 105,93 gram dan ulangan 3 adalah 127,04 gram.

Pada kelas umur IV terjadi peningkatan produktivitas getah dari 3 kali ulangan. Sedangkan pengambilan getah pada kelas umur V produktivitas getahnya menurun pada ulangan ke 2 diameter 20-23 lebih besar dari diameter 24-27 dengan selisih 1,75 gram dan pada kelas umur VI produktivitas getahnya menurun pada ulangan ke 1 diameter 24-27 lebih besar dari diameter 28-31 dengan selisih 19,44 gram dikarenakan pada waktu pengambilan getah dalam keadaan hujan sehingga air yang diserap oleh pohon meningkat mempengaruhi produktivitas getah yang dihasilkan lebih sedikit. Sedangkan pada musim kemarau terjadi peningkatan produktivitas getah dikarenakan daya serap air yang sedikit.

Tabel 1. Rata-rata Produktivitas Getah Pinus merkusii di setiap Kelas Umur (KU)

\begin{tabular}{|c|c|c|c|c|c|c|c|}
\hline \multirow{2}{*}{ No } & \multirow{2}{*}{$\begin{array}{l}\text { Kelas } \\
\text { Umur } \\
(\mathbf{K U})\end{array}$} & \multirow{2}{*}{$\begin{array}{c}\text { Ulangan } \\
\text { Pengambilan } \\
\text { Getah }\end{array}$} & \multicolumn{3}{|c|}{ Kelas Diameter } & \multirow{2}{*}{$\begin{array}{c}\text { Rata-rata } \\
\text { Getah }\end{array}$} & \multirow{2}{*}{ Ket } \\
\hline & & & $20-23$ & 24-27 & 28-31 & & \\
\hline \multirow[t]{4}{*}{1.} & IV & 1 & 36,25 & 44,00 & 60,00 & 46,75 & \\
\hline & & 2 & 10,00 & 11,00 & 16,00 & 12,33 & \\
\hline & & 3 & 22,50 & 25,00 & 26,00 & 24,55 & \\
\hline & Rata & a IV & 22,92 & 26,67 & 34,00 & 27,86 & \\
\hline \multirow[t]{4}{*}{2.} & $\mathrm{~V}$ & 1 & 45,00 & 52,00 & 71,00 & 56,00 & \\
\hline & & 2 & 58,75 & 57,00 & 64,00 & 59,92 & \\
\hline & & 3 & 71,25 & 75,00 & 76,00 & 74,08 & \\
\hline & Rata & ta $V$ & 58,33 & 61,33 & 70,33 & 63,33 & \\
\hline \multirow[t]{4}{*}{3.} & VI & 1 & 130,00 & 160,00 & 140,56 & 143,52 & \\
\hline & & 2 & 70,00 & 110,00 & 137,78 & 105,93 & \\
\hline & & 3 & 115,00 & 130,00 & 136,11 & 127,04 & \\
\hline & Rata & a VI & 105,00 & 133,33 & 138,15 & 125,49 & \\
\hline
\end{tabular}

Berikut ini data rata-rata produktivitas getah Pinus merkusii pada KU (Kelas Umur) IV, KU (Kelas Umur) V dan KU (Kelas Umur) VI pada Gambar 1.

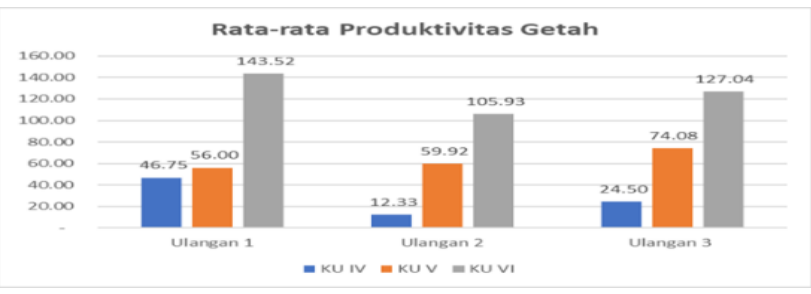

Gambar 1. Rata-rata Produktivitas Getah

Gambar 1 menyatakan bahwa rata-rata produktivitas getah pinus merkusii pada setiap ulangan menunjukkan bahwa KU (Kelas Umur) VI produktivitas getahnya lebih tinggi dibandingkan dengan KU (Kelas Umur) V dan KU (Kelas Umur) IV. Periode (ulangan) pemungutan getah memberikan pengaruh yang nyata terhadap produktivitas rata-rata di setiap kelas umur (KU). Periode pemungutan getah yang pertama, kedua dan ketiga memberikan hasil yang berbeda nyata. 
Perbedaan produksi rata-rata getah pinus pada pemungutan periode pertama lebih tinggi dibandingkan dengan periode kedua, selanjutnya periode ketiga cenderung meningkat, hal ini diduga karena adanya pengaruh iklim yang meningkat yaitu dengan turunnya hujan sehingga suhu yang dingin akan menyebabkan pengeringan getah yang kemudian memperlambat aliran getah.

\section{Perhitungan Produktivitas Getah Menggunakan SPSS}

Hasil perhitungan produktivitas getah menggunakan software SPSS tersaji pada Tabel 2. Tabel 2 menyatakan bahwa nilai-nilai penting yang bisa disimpulkan sebagai berikut:

\section{a. Kelas Umur}

Pengaruh kelas umur terhadap produktivitas getah di dalam model. Apabila Signifikansi (Sig.) $<0,05$ (Alfa) $=$ Signifikan. Hasil di atas 0,000 berarti kelas umur berpengaruh signifikan.

\section{b. Diameter}

Pengaruh diameter terhadap produktivitas getah di dalam model. Apabila Signifikansi (Sig.) $<0,05$ (Alfa) $=$ Signifikan. Hasil di atas 0,05 berarti diameter berpengaruh signifikan.

Tabel 2. Analisis Sidik Ragam

\begin{tabular}{|c|c|c|c|c|c|}
\hline Sumber & $\begin{array}{c}\text { Jumlah } \\
\text { Kuadrat }\end{array}$ & df & Rata-rata & $\mathbf{F}$ & Sig. \\
\hline Model terkoreksi & $11246,470^{\mathrm{a}}$ & 8 & 1405,809 & 19,336 & ,000 \\
\hline Intercept & 33182,888 & 1 & 33182,888 & 456,411 &, 000 \\
\hline Kelas Umur & 10580,793 & 2 & 5290,396 & 72,766 & ,000 \\
\hline Diameter & 404,661 & 2 & 202,331 & 2,783 & ,05 \\
\hline Kelas Umur * & 261,061 & 4 & 65,254 & ,898 & ,486 \\
\hline \multicolumn{6}{|l|}{ Diameter } \\
\hline Galat & 1308,671 & 18 & 72,704 & & \\
\hline Total & 45738,029 & 27 & & & \\
\hline Total terkoreksi & 12555,141 & 26 & & & \\
\hline
\end{tabular}

Dari hasil analisa di atas, dalam uji Anova bahwa kelas umur dengan diameter berpengaruh secara signifikan. Untuk memperkuat hasil uji anova maka dilakukan Uji lanjut. Uji yang digunakan untuk uji lanjut yaitsu uji Duncan. Hasil yang diperoleh dari uji Duncan pada Table 3.

Dari uji lanjut diatas diperoleh hasil bahwa pada Kelas Umur (KU) VI menghasilkan produksi getah yang paling tinggi yaitu 61,17gram. Data diatas menunjukan semakin tua maka produktivitas getah yang dihasilkan juga lebih banyak. Maka semakin tua umur pohon ada kecenderungan produksi getah akan 
meningkat sampai umur tertentu. Produktivitas getah pinus merkusii dapat dipengaruhi oleh faktor-faktor yang berkaitan dengan kualitas lahan, diantaranya adalah umur, diameter, ketinggian, kerapatan tegakan, kesuburan lahan (bonita), luas areal sadap, jumlah koakan dan keterampilan penyadap getah (Susanto, 2011).

Tabel 3. Hasil Uji Lanjut Duncan Kelas Umur

\begin{tabular}{ccc}
\hline No & Kelas Umur & $\begin{array}{c}\text { Produktivitas Getah } \\
\text { (gram) }\end{array}$ \\
\hline 1 & IV & $13,26^{\mathrm{c}}$ \\
2 & V & $30,74 \square$ \\
3 & VI & $61,17^{\mathrm{a}}$ \\
\hline
\end{tabular}

\section{Pengaruh Diameter}

Diameter akan mempengaruhi produktivitas getah yang dihasilkan, oleh karena itu dilakukan uji lanjutan Duncan untuk mengetahui kelompok diameter yang berpengaruh terhadap produktivitas getah secara signifikan.

\begin{tabular}{ccc}
\multicolumn{2}{c}{ Tabel 4. Hasil Uji Lanjut Duncan Diameter } \\
\hline No & Diameter & $\begin{array}{c}\text { Produktivitas Getah } \\
\text { (gram) }\end{array}$ \\
\hline 1 & $20-23$ & $29,7 \square$ \\
2 & $24-27$ & $36,44^{\mathrm{a}} \square$ \\
3 & $28-31$ & $38,95^{\mathrm{a}}$ \\
\hline
\end{tabular}

Dari uji lanjutan di atas diperoleh hasil bahwa pada diameter 28-31 menghasilkan produksi getah yang paling tinggi yaitu 38,95 gram. Data diatas menunjukan semakin besar diameter maka produktivitas getah yang dihasilkan juga lebih banyak.

Dari penelitian ini pohon pinus yang akan disadap menggunakan cara diameter minimum yaitu pemilihan pohon pinus yang akan disadap yang memiliki diameter di atas $20 \mathrm{~cm}$ yaitu sekitar $20 \mathrm{~cm}-31 \mathrm{~cm}$. Cara ini dimaksudkan agar pengambilan getah pada setiap riap tumbuh pohon agar tercapai produksi getah yang maksimum dan tidak mengganggu pertumbuhannya.

Produktivitas getah pinus merkusii berhubungan dengan pertumbuhan diameter pohon. Sehingga dengan adanya pertumbuhan diameter pohon, menyebabkan volume kayu gubal semakin besar. Oleh karena itu semakin besar volume kayu gubal, maka saluran getah yang terkandung pada pohon pinus akan meningkat. Dan perbedaan kelas umur pohon berpengaruh terhadap jumlah produksi getah, semakin bertambah umur pohon, maka diameter kayu akan bertambah sehingga getah yang dihasilkan akan lebih banyak, sampai batas umur tertentu (Wibowo, 2006). 
Getah yang dihasilkan pohon Pinus merkusii digolongkan sebagai oleoresin yang merupakan cairan asam-asam resin dalam terpentin yang menetes ke luar apabila saluran resin pada kayu atau kulit pohon jenis daun jarum tersayat atau pecah. Penamaan oleoresin ini dipakai untuk membedakan dari getah (natural resin) yang muncul pada kulit atau dalam rongga-rongga jaringan kayu dari berbagai genus anggota Dipterocarpaceae atau Leguminoceae dan Caesalpiniaceae (Hillis, 1987 dalam Adhi, 2008). Menurut Aritonang (2013), saluran getah resin bukan merupakan bagian dari kayu, tetapi berupa rongga yang dikelilingi oleh sel-sel parenkimatis atau sel epitel. Seluruh lapisan yang mengelilingi saluran resin disebut epitellium. Mariana (2008) menambahkan, saluran resin adalah suatu saluran yang terdapat pada saluran pohon pinus, maka getah yang mengandung resin akan keluar melaluinya, saluran ini ada apabila pohon pinus dilukai.

Penelitian produksi getah pinus dengan penyadapan metode koakan atau metode quarre telah dilakukan oleh Leksono (1994) dalam Sukarno et al (2012) di Jember dan Sumedang dengan produksi getah rerata $21,8 \mathrm{~g} / 7$ hari/pohon dan Wibowo (2006) di Jawa Barat dengan produksi rata-rata getah pinus yang dihasilkan pada kelas diameter IV 35 up cm sebesar 12,084 gr/pohon/hari. Hasil penelitian tersebut berbeda dengan hasil penelitian ini, hal ini diduga disebabkan oleh perbedaan ukuran diameter, umur, cuaca dan tempat tumbuh. Hal ini didukung oleh pendapat Setyowiharto (2008), bahwa potensi produksi getah dari suatu tegakan pinus cenderung bervariasi, yang disebabkan karena perbedaan umur, ketinggian tempat tumbuh, diameter, luas bidang dasar, dan faktor-faktor lainnya. Hal yang sama juga dinyatakan oleh Lestari (2012), produktivitas getah pinus dipengaruhi oleh beberapa faktor antara lain faktor dari dalam pohon itu sendiri seperti jenis, diameter dan umur tegakan.

Menurut Hutabalian et al. (2015), semakin besar diameter maka semakin besar produksi getah yang dihasilkan, sebaliknya semakin kecil diameter maka semakin sedikit produksi getah yang dihasilkan. Ketinggian tempat tumbuh pohon pinus dari permukaan laut akan mempengaruhi produksi getah. Semakin tinggi tempat tumbuh maka getah akan menggumpal dan aliran getah akan terhambat karena rendahnya suhu udara dan intensitas cahaya matahari, sehingga produksi getah menurun (Rochidayat dan Sukawi, 1979 dalam Setyowiharto, 2008). Arsal (2008) menambahkan, pohon pada kelerengan yang lebih tinggi cukup mendapatkan sinar matahari yang memungkinkan pohon dapat melakukan aktivitas fotosintesis dengan baik untuk pertumbuhannya, dan apabila koakan yang dibuat pada pohon pinus terkena sinar matahari maka getah pinus tersebut tidak akan menggumpal sehingga saluran resin tidak akan tertutup oleh gumpalan 
getah tersebut. Dikarenakan, P. merkusii tergolong jenis yang membutuhkan cahaya sinar matahari secara penuh (jenis heliophytes) dalam proses pertumbuhannya.

Berkurangnya intensitas dan pendeknya waktu cahaya matahari yang diterima dapat menghambat pertumbuhan pohon, karena kegiatan fotosintesa menjadi menurun (Salatta, 2013). Sofyan (1999) dalam Listyandari (2009), produksi getah pinus selain dipengaruhi oleh ketinggian tempat juga dipengaruhi umur pohon. Semakin tua suatu pohon pinus maka semakin tinggi produksi getah yang dihasilkan. Tegakan Pinus merkusii yang berumur tua cenderung menghasilkan getah yang lebih banyak daripada yang berumur muda. Doan (2007), curah hujan akan mempengaruhi kelembaban sekitar luka sadapan. Curah hujan yang tinggi akan menyebabkan kelembaban disekitar luka sadapan menjadi tinggi dan hal tersebut dapat menyebabkan getah cepat mengumpal.

Produktivitas getah pinus merkusii dipengaruhi oleh faktor internal dan ekternal. Faktor internal berupa tempat tumbuh serta tindakan dalam pemeliharaan hutan. Salah satu aspek eksternal yang berpengaruh ialah tenaga penyadap, ketrampilan penyadap, dan pengalaman penyadap. Kasmudjo (2001) bahwa ada beberapa faktor tenaga penyadap yang mempengaruhi terhadap produktivitas:

a. Musim hujan yang terus menerus menyebabkan suhu udara rendah sehingga getah cepat membeku, para penyadap kurang efektif jika menyadap getah pada musim hujan.

b. Jarak dari desa ke blok sadapan terlalu jauh, yang menyebabkan lamanya interval pembaharuan luka/quare, sehingga getah yang dihasilkan pada masingmasing pohon kurang optimal.

\section{SIMPULAN}

1. Produktivitas getah pinus merkusii dipengaruhi kelas umur. Hal ini ditunjukan oleh data kenaikan kelas umur yang diikuti dengan meningkatnya produktivitas getah. Semakin tua umur pohon ada kecenderungan produksi getah akan meningkat sampai umur tertentu.

2. Diameter berpengaruh terhadap produktivitas getah, semakin besar pertumbuhan diameter pohon maka saluran getah yang terkandung akan semakin banyak dan produksi getah pinus akan meningkat. 


\section{DAFTAR PUSTAKA}

Adhi Y.A. (2008). Pengaruh Jumlah Sadapan Terhadap Produksi Getah Pinus (Pinus merkusii) Dengan Metode Koakan Di Hutan Pendidikan Gunung Walat Kabupaten Sukabumi Jawa Barat. (Skripsi). Departemen Hasil Hutan Fakultas Kehutanan, Institut Pertanian Bogor.

Aritonang W. (2013). Peluang Usaha Getah Pinus Dalam Pasar Industri Domestic dan Internasional. Retrieved from http://hutanb2011. blogspot.co.id/2013/06/ peluang-usahagetah-pinus-dalam-pasar.html.

Doan ANG. (2007). Ciri-ciri Fisik Pinus (Pinus merkusii Jungh et de Vriese) Banyak Menghasilkan Getah dan Pengaruh Pemberian Stimulansia serta Kelas Umur terhadap Produksi Getah Pinus di RPH Sawangan dan RPH Kemiri KPH Kedu Selatan, Perum Perhutani Unit I Jawa Tengah. (Skripsi). Institut Pertanian Bogor, Bogor.

Hutabalian J.P., Batubara R., Dalimunthe A. (2015). Pengaruh Diameter dan Konsentrasi Stimulansi Asam Cuka (C2H4O2) Terhadap Produktivitas Getah Pinus (Pinus merkusii Jungh et de Vriese) (Effect of Diameter and Concentration of Stimulansia Vinegar Acid (C2H4O2) Pine Sap Productivity (Pinus merkusii Jungh et de Vriese). Peronema Forestry Science Journal, 4(3).

Kasmudjo. (2001). Usaha Stimulasi Pada Penyadapan Getah Pinus. Duta Rimba. Lempang, Mody. (2017). Study Penyadapan Getah Pinus Cara Bor Dengan Stimulan H2SO4 (study of Pine Resin Tapping by Drilling Using H2SO4 Stimulant). $\quad$ Retrieved from https://media.neliti.com/media/publications/197513-ID-tudi-penyadapangetah-pinus-cara-bor-de.pdf.

Lestari L. (2012). Pengaruh Periode Pelukaan Pada Penyadapan Getah Pinus Dengan Metode Bor Di Hutan Pendidikan Gunung Walat Kabupaten Sukabumi Jawa Barat. (Skripsi). Institut Pertanian Bogor, Bogor.

Listyandari A.K. (2009). Pengelolaan Tegakan Pinus Di Taman Nasional Gunung Merapi (Studi Kasus Penyadapan Getah Pinus oleh Masyarakat Desa Ngargomulyo, Kabupaten Magelang, Jawa Tengah). (Skripsi). Institut Pertanian Bogor, Bogor.

Listyandari A.K. (2009). Pengelolaan Tegakan Pinus Di Taman Nasional Gunung Merapi (Studi Kasus Penyadapan Getah Pinus oleh Masyarakat Desa Ngargomulyo, Kabupaten Magelang, Jawa Tengah). (Skripsi). Institut Pertanian Bogor, Bogor.

Mariana. (2008). Teknik Dan Waktu Penyadapan Terhadap Produksi Getah Pinus (Pinus merkusii Jung et de Vries) Di Desa Uwemanje Kecamatan Marawola 
Kabupaten Donggala. Skripsi. Program Studi Manajemen Hutan Jurusan Kehutanan Fakultas Pertanian, Universitas Tadulako.

Salatta M.K. (2013). Pinus (Pinus merkusii Jungh et de Vriese) dan Keberadaannya di Kabupaten Tana Toraja, Sulawesi Selatan. Info Teknis EBONI 10(2).

Setyowiharto A. (2008). Penyusunan Model Penduga Potensi Getah Pinus (Pinus merkusii Jungh. et De Vriese) Di KPH Cianjur PERUM PERHUTANI Unit III Jawa Barat dan Banten. (Skripsi). Institut Pertanian Bogor, Bogor.

Sukarno A., Hardiyanto E.B., Marsoemi S.N., Na'iem M. (2012). Pengaruh Perbedaan Kelas Umur terhadap Produktivitas Getah Pinus merkusii Jungh et de Vriese Ras Lahan Jawa melalui Penyadapan Getah Metode Bor (Effect Of Among Age Class Differences On Oleoresin Production Pinus merkusii Jungh et de Vriese Java Land Race Tapping By Drill Method). J-PAL3(1).

Sutanto R. (2011). Dasar-dasar Ilmu Tanah. Yogyakarta: Kanisius

Wibowo P. (2006). Produktivitas Penyadapan Getah Pinus Merkusii Jungh et de Vriese dengan Sistem Koakan (Quare System) di Hutan Pendidikan Gunung Walat Kabupaten Sukabumi Jawa Barat. (Skripsi). Institut Pertanian Bogor, Bogor. 